\title{
Para uma análise existencial da saúde
}

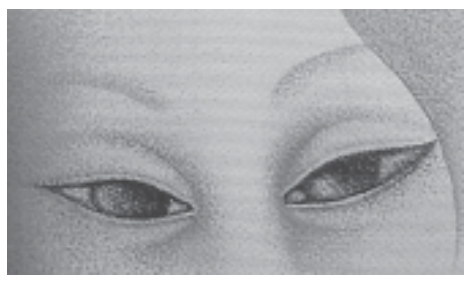

Roberto Passos Nogueira ${ }^{1}$

NOGUEIRA, R. P. An existential analysis of health. Interface - Comunic., Saúde, Educ., v.10, n.20, p.333-45, jul/dez 2006.

Heidegger's fundamental ontology in Being and Time has been used as an invaluable source of inspiration for researchers in the areas of mental and collective health, in spite of the difficulty in interpreting it. Binswanger's misunderstanding of this work, in the attempt to transpose it to psychoanalysis, is an great example of such and briefly discussed based on Loparic's in depth study. In this article, the author assumes that Heidegger's anti-metaphysical language can help bridge what he refers to as the false ontological gap between mental health and physical health. In the first half, the article revisits some common misinterpretations related to Heidegger's ontology, and outlines criteria pertaining to non-objection and non-determination. Subsequently the author provides his contribution, expounding his own interpretation regarding existential ontological analysis of health, using terms such as ailing, aiding and recovery.

KEY WORDS: ontology. health-disease process. existentialism.

A ontologia fundamental de Heidegger de Ser e Tempo tem servido de fonte de inspiração para investigadores que realizam seus trabalhos nas áreas de saúde mental e saúde coletiva, a despeito das dificuldades de interpretação dessa obra. O entendimento equivocado por Binswanger, na tentativa de transpô-la para a psicanálise, serve de exemplo e é brevemente exposto com base na análise detalhada feita por Loparic. Neste artigo, parte-se do pressuposto de que a linguagem antimetafísica de Heidegger pode ajudar a fechar o que denomina de fenda ontológica entre saúde mental e saúde do corpo. Na primeira parte, recapitulam-se alguns equívocos que podem ser cometidos na interpretação da ontologia heideggeriana e delineiam-se os critérios de não-objetivação e não-determinismo. Na segunda, o autor aporta sua contribuição pessoal, ao explicitar sua própria interpretação da analítica existencial da saúde, articulada em torno de termos, tais como: padecimento, socorro e reatamento.

PALAVRAS-CHAVE: ontologia. processo saúde-doença. existencialismo.

\footnotetext{
${ }^{1}$ Núcleo de Estudos de Saúde Pública, Universidade de Brasília. <roberto.nogueira@ipea.gov.br>
} 


\section{Introdução}

Desde sua publicação, em 1927, Ser e Tempo, de Heidegger, é uma obra que tem servido de inspiração para muitos que investigam a saúde pelo prisma das Ciências Humanas. Os primeiros a serem atraídos pela ontologia heideggeriana foram os psiquiatras e psicanalistas com têmpera filosófica. O mais proeminente talvez tenha sido Binswanger (1881-1966), psiquiatra suíço que elaborou uma doutrina que partia, de forma direta, embora criticamente, da análise do Dasein (Loparic, 2002). A psiquiatria daseinanalítica de Binswanger entendia que a essência do homem não consiste apenas de um "ser-no-mundo", que é um "ser-para-a-morte", marcado por sua contingência, conforme descrito por Heidegger (Loparic, 2002). Em Formas fundamentais e conhecimento do Dasein humano, de 1942, Binswanger propõe uma reinterpretação segundo a qual o Dasein humano ${ }^{2}$ projeta-se igualmente numa condição cósmica, universal $e$ permanente, que se fundamenta na disposição do amor. Portanto, o Dasein seria um ser-no-mundo-para-além-do-mundo. Ele pretendia que esse tipo de adendo à obra de Heidegger resultasse não de uma abordagem de filosofia moral, mas de um desenvolvimento teórico do mesmo nível ontológico de Ser e Tempo.

Boss, da Universidade de Zurich, foi seguidor de Binswanger $e$ introduziu diversas modificações em sua doutrina. Ele tornou-se amigo de Heidegger e os dois mantiveram uma longa correspondência pessoal. Por dez anos, a partir de 1959, Boss devotou-se a organizar, onde morava, em Zollikon, encontros de Heidegger com um grupo de médicos e outros profissionais convidados, durante os quais se discutiam as questões da fenomenologia e sua relação com a teoria e prática da psicanálise (Heidegger, 2001b).

No Brasil, a reflexão sobre a obra heideggeriana em conexão com esta $e$ outras teorias psicanalíticas vem-se difundindo há pelo menos duas décadas. Há uma Associação Brasileira de Daseinanalyse (ABD) que divulga trabalhos de Boss e estudos originais de autores nacionais sobre o tema; em algumas universidades já existem centros de pesquisa e debate sobre Heidegger e psicanálise, devendo ser destacado o Grupo de Filosofia e Práticas Psicoterápicas, sob a orientação do professor Loparic, da Universidade de Campinas. Loparic é um entusiasta da psicanálise do amadurecimento humano, desenvolvida por Winnicott, a quem considera ser o único autor cuja contribuição científica no campo da psicanálise é compatível com a ontologia heideggeriana, embora reconheça que Winnicott não foi diretamente influenciado por Heidegger ou por qualquer outro filósofo.

Fora das disciplinas da saúde mental, vamos encontrar, no Brasil, um interesse crescente por Heidegger e pelos demais autores da linhagem hermenêutica nos pesquisadores da saúde coletiva. Um dos focos desse interesse tem sido a questão do cuidado em saúde, para a qual se pretende desenvolver referenciais adequados, levando em conta seus aspectos éticos e técnicos (Ayres, 2003, 2004; Bressan \& Scatena, 2002). Mas também têm destaque os temas da relação saúde-doença (Caprara, 2003), do cuidado no âmbito da promoção da saúde (Ayres, 2004), bem como da
${ }^{2}$ Esta expressão é um pleonasmo, já que não existe o Dasein dos animais, mas não foi evitado nem em Ser e Tempo, como nota Heidegger (2001b, p. 146). 
abordagem hermenêutica e fenomenológica de problemas específicos de saúde (Lopes \& Souza, 1997; Caprara \& Veras, 2005). A saúde coletiva brasileira vem deixando claras as implicações éticas e metodológicas desses temas para a organização dos cuidados na clínica médica e na prática da saúde pública. Novos investigadores vêm adentrando nesses campos de saber que até pouco tempo atrás praticamente só eram freqüentados pelos psicanalistas. Por outro lado, em sintonia com o horizonte filosófico, aparece já um anseio de buscar apoio interpretativo nos fatos ônticos da saúde e da doença, inclusive, nas formas específicas de adoecimento. Outra linha de esforço interpretativo aponta para a necessidade de estender e aprofundar os estudos propriamente hermenêuticos e ontológicos da saúde, que partam da singularidade da vivência humana da enfermidade.

Este artigo pretende contribuir com o campo da investigação filosófica sobre fenômenos do adoecimento humano que estão articulados com a estrutura geral do Dasein. Um pressuposto é que, sem a compreensão desse plano existencial da saúde, estaremos sempre esbarrando nas elaborações metafísicas tradicionais que predefinem todos os fenômenos como relações entre entes objetivos e, que, no caso da medicina, aparecem na classificação das enfermidades por tipos e variantes.

No meu entender, a questão central da analítica existencial da saúde é a fenda ontológica criada entre saúde mental e saúde do corpo. A crítica ao determinismo freudiano avançou até o ponto em que as teorias da psicanálise abraçaram, nas décadas, um não-determinismo que é próprio da compreensão do Dasein, como já se evidencia em Winnicott. Mas o que dizer das enfermidades somáticas? Estão para sempre fadadas a serem compreendidas numa ótica determinista, apenas relativizada pelo multicausalismo, como quer a epidemiologia? Esse tipo de dualismo leva a entender que, quando acometido de problemas mentais, o homem realiza sua liberdade de escolher seu ser, mas algo semelhante não ocorre quando sofre de problemas corporais. O corpo humano continuaria a ser interpretado pela ontologia reificadora das ciências naturais: é uma coisa no meio de outras e está determinado por causas precisas (vírus, genes, ambiente etc.). Pode o entendimento das doenças do corpo ser objetivista e determinista, enquanto, em contrapartida, o entendimento da saúde mental há tempo se abriu para uma interpretação não-determinista e não-objetivante? É esta a fenda ontológica que precisa ser fechada em qualquer análise existencial da totalidade da saúde orientada pela ontologia heideggeriana.

Fica cada vez mais claro que a enfermidade do corpo (chame-a como se quiser) não é essa espécie de soma de causas e sinais (por exemplo: lesão + sintomas + agentes físicos), mas é o produto das escolhas do Dasein, em relação a todas as pessoas e todos seus afazeres como ser-no-mundo. Ainda quando se diz comumente que a enfermidade física não é um ente, mas um processo, não se resolve o problema, porque na compreensão da ciência $e$ da filosofia ocidentais, em todo processo, são pressupostos relacionamentos de objetos com objetos. Tampouco está resolvido quando se fala do paciente como sujeito da sua saúde. Isto porque o sujeito, segundo a ontologia cartesiana, que serve de fundamento para a ciência moderna, nada mais é que um ente pensante entre os demais entes do mundo (Heidegger, 2001a). Não temos, então, como evitar as armadilhas que se armam em todos os planos de 
análise pelo fato de a linguagem estar profundamente imbuída da ontologia tradicional. É justamente por esse motivo que, para tratar da totalidade existencial do Dasein, Ser e Tempo teve de inaugurar sua própria linguagem, que busca eliminar todas as dicotomias que resultam da distinção de relações entre objetos ou entre sujeitos e objetos, como resultado da uma crítica fenomenológica à epistemologia de Descartes e Kant.

Assim, a questão que deve ser colocada inicialmente no plano da compreensão nitidamente filosófica é esta: é possível elaborar, com base em Ser e Tempo, um tipo de interpretação que ajude a cobrir a fenda entre saúde mental e saúde do corpo? Tendo em conta esta questão (que bem sei representar um enorme desafio de elaboração filosófica), proponho-me a realizar um curto experimento com a linguagem ontológica de Heidegger, falando da totalidade existencial da saúde nesse idioma. Por exemplo, o termo padecimento indica o conjunto de fenômenos defectivos tanto da saúde mental quanto da saúde física. Mas deve ficar bem claro, para o leitor, que todas as palavras e noções propostas neste experimento não fazem parte do vocabulário original de Heidegger, nem se relacionam diretamente com suas cogitações fenomenológicas, expressas em Ser e Tempo e outras obras.

Estou ciente de ter me envolvido num experimento arriscado, porque a linguagem de Heidegger está prenhe de sutilezas semânticas e léxicas, que decorrem do rigor que exigiu de si no desenvolvimento de sua ontologia fundamental, e os equívocos de "adaptação" e de "inovação" podem ser cometidos a cada passo. Por isto, o artigo é parcimonioso e propõe um número reduzido de aportes interpretativos. Neste sentido, representa apenas um esboço de um projeto de análise existencial da saúde, que o autor espera ulteriormente desenvolver com mais precisão e detalhe.

\section{Equívocos de leitura e critérios de investigação}

Nos encontros de Zollikon, Heidegger fez críticas mais ou menos ácidas às interpretações de Ser e Tempo por Binswanger. Afirmou, por exemplo, que ele não percebeu que o amor não tem, tal como o cuidado, um primado ontológico, e que não pode pertencer de direito a uma compreensão da estrutura ontológica do Dasein. Binswanger reconheceu, posteriormente, que havia cometido um erro ao conceder ao amor um estatuto ontológico fundamental para o "ser-no-mundo", mas que esse havia sido um equívoco produtivo porque o ajudara a conceber a abordagem psiquiátrica da daseinanálise, em que a fenomenologia do amor tem importância crucial.

Nessa crítica a Binswanger, Heidegger (2001b) deixa claro que a questão do "ser-no-mundo" é inseparável da compreensão do ser, e que tal compreensão está ausente na obra desse médico-filósofo, que baseou sua análise apenas na constituição fundamental do ser-no-mundo. Não basta determinar o Dasein como ser-no-mundo: é preciso ter a compreensão da questão do ser do Dasein, que enquanto um ser-aí se encontra numa relação privilegiada com o ser $e$ com sua compreensão.

Resumidamente, as críticas de Heidegger apontam para dois tipos de equívoco na leitura de Ser e Tempo: a) querer agregar fenômenos ônticos de uma maneira não articulada ou conflitante com a estrutura existencial do 
Dasein: não se pode ignorar, por exemplo, que o amor é uma realização ôntica do modo essencial de ser do Dasein, que é o cuidado (sorge); b) querer derivar compreensões extensivas $e$ isoladas de um único existencial (ser-no-mundo): é preciso ter em conta todos os existenciais que compõem a estrutura fundamental do Dasein que estão em conexão com a questão do ser, tais como: o cuidado, a angústia, a temporalidade e o ser-para-a-morte.

Mas há, também, problemas de ordem epistemológica e metodológica a serem considerados. Toda nova interpretação afinada com a crítica heideggeriana das ciências naturais e que tenha a ver com fenômenos antropológicos, incluindo, portanto, a questão do patológico, deve atender a alguns critérios. Segundo Loparic (2002), tais critérios são apenas em número de dois e de caráter negativo, a saber: não-objetivação e nãodeterminismo. Isto quer dizer que não se pode falar do homem como se fosse um ente a mais na paisagem do mundo, definido por suas relações com tudo que o cerca. Numa abordagem dos fenômenos de saúde e doença que aspire ser consistente com a ontologia fundamental, a interpretação tem de partir do seguinte pressuposto: o homem pode experimentar limitações ou dificuldades de ser o que ele é em essência. Estas são dificuldades de existir à altura da liberdade do Dasein.

Loparic (1999) afirma que a psicanálise de Winnicott pode ser entendida como uma efetivação não-intencional do projeto heideggeriano de uma patologia e de uma terapia daseinanalíticas. É a única abordagem que, em sua opinião, satisfaz esses critérios epistemológicos e metodológicos de uma ciência do homem (incluindo, portanto, a ciência do normal e do patológico).

Pela teoria winnicottiana, o amadurecimento tem início num ponto em que a criança está enlaçada numa condição em que não é nem idêntica nem realmente distinta da mãe. É longo o caminho percorrido pela criança para perceber-se como independente da mãe e dos entes que compõem o mundo, experimentando com sua liberdade. A criança "cria" a externalidade das coisas e dos seres que são semelhantes a ela, ao mesmo tempo em que desenvolve um sentido de identidade própria e de liberdade de escolha. Esse percurso da criança só é possível porque existe alguma coisa permanente e fundadora da experiência existencial do amadurecimento, que é a natureza humana, caracterizada por um potencial próprio de crescimento e de tendência à condição de unidade (integração). Loparic conclui que, em Winnicott, o processo de maturação só se realiza a partir de necessidades não-causais do ser e que tem, como contrapartida, uma presença devotada de outros seres humanos, que também é de tipo não-causal. Por isto, a única coisa que a psicanálise pode fazer é ajudar para que cada um faça o reencontro com o que Winnicott chama de natureza humana, com seu potencial intrínseco de maturação e integração.

A pergunta que se pode fazer, neste ponto, é a seguinte: do ponto de vista da ontologia heideggeriana, a que remete esse reencontro com a natureza humana, à medianidade do modo de ser impessoal como cotidianidade do serno-mundo, ou às possibilidades de singularização asseguradas pelo modo de ser próprio e pessoal do Dasein? Esta questão não fica clara na exposição de Loparic, apesar de sua insistência na grande afinidade entre a visão científica de Winnicott $e$ a visão filosófica de Heidegger.

Mas o que é, afinal, uma análise existencial da saúde? Nas palavras de 
Heidegger (2001b, p. 141), "a analítica tem a tarefa de mostrar o todo de uma unidade de condições ontológicas. A analítica como analítica ontológica não é um decompor em elementos, mas a articulação da unidade de uma estrutura". Contudo, a analítica existencial da saúde não aporta algo essencialmente novo para a compreensão da estrutura ontológica do Dasein, embora tenha de partir dela. Todos os existenciais ${ }^{3}$ que interessam a uma antropologia filosófica da saúde já estão presentes nessa obra. O que uma antropologia filosófica da saúde busca acrescentar, enquanto análise de uma "região" do Dasein, é uma adequada articulação desses existenciais, mediante certas modalizações existenciárias que permitem interpretar os fenômenos ônticos das enfermidades e dos sofrimentos humanos a elas associados, já que estes são fenômenos de singularização do ser.

No entanto, a saúde, enquanto tal, recobre um amplo território de interpretação do Dasein, que já está por inteiro contido em Ser e Tempo. Entendo que, com base nessa obra, é possível distinguir o que de fato caracteriza ontologicamente a saúde. E se sabemos o que é a saúde, fica mais fácil sabermos o que é a sua privação, a doença. Contudo, o estar doente é sempre uma forma singular de ser; por isto, os fenômenos da enfermidade não podem fazer parte da estrutura geral de compreensão do Dasein. Tais fenômenos só são acessíveis pela compreensão dos modos existenciários do ser doente.

Creio que foi algo assim que Heidegger (2001b, p.73-4) quis dizer sobre essa questão, numa de suas exposições nos Seminários de Zollikon, embora tenha tratado do assunto de forma tangencial:

\begin{abstract}
A doença é um fenômeno de privação. Em toda privação, está a co-pertinência essencial, aquilo a que falta algo, de que algo foi suprimido. Isto parece uma trivialidade, mas é extremamente importante justamente porque a profissão dos senhores movese neste âmbito. Na medida em que os senhores lidam com a doença, na verdade, os senhores lidam com a saúde, no sentido da saúde que falta e deve ser recuperada. (...) Assim, também o estar-não-são, o estar doente é uma forma privativa do existir. Por isso, não se pode conceber adequadamente a essência do estar doente sem uma determinação suficiente do estar são.
\end{abstract}

A “determinação suficiente do estar são", no meu entender, está contida nas análises de Ser e Tempo. Uma analítica existencial da saúde deveria dar conta das duas alternativas de compreensão ontológica da saúde, que aí podem ser encontradas: a) a saúde como o recuperar das possibilidades do ser do Dasein na medianidade do cotidiano; e b) a saúde como a abertura do Dasein para as possibilidades que lhe são mais próprias, possibilidades colocadas no horizonte temporal da antecipação da morte e fundadas na angústia. Isto leva a considerar que há uma saúde que corresponde ao modo impessoal e não-próprio de ser, assim como há uma saúde que corresponde ao modo próprio e pessoal de ser.

Como primeira aproximação à analítica existencial da saúde, trato de caracterizar alguns modos existenciários em que essas duas alternativas se

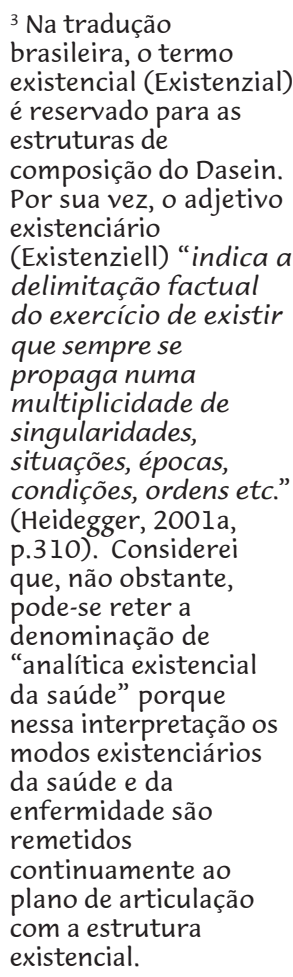


${ }^{4}$ Todas as referências breves e marcantes, colocadas entre parênteses, são extraídas de Sere Tempo. apresentam para o Dasein. Mas evitei incluir a análise da relação terapeutapaciente, da ajuda e do próprio significado do cuidado em saúde. O que coloquei em primeiro lugar é a auto-apreensão da saúde, como saúde para si mesmo, que considero ser o modo próprio de indagar numa investigação existencial da saúde.

\section{Anotações preliminares para uma analítica existencial da saúde}

A postura existencial própria à saúde. A maioria dos estudos e das práticas de saúde é feita na terceira pessoa. A saúde é algo que pertence aos outros: na clínica, pertence aos pacientes, na epidemiologia, à população em geral. Neste caso, quem pretende conhecer ou questionar a saúde apenas procura saber e avaliar o que acontece com os outros. Ao contrário, num posicionamento existencial da saúde, cada um tem de se reconhecer em jogo em tudo o que se refere à saúde.

Assim, para que eu tenha a intuição existencial da saúde, é preciso que eu a assuma como algo que compõe a compreensão do meu ser no mundo. A saúde, de modo ainda incompleto, mas já bem claro, é dada na espontânea compreensão existencial do ser: estou bem ou estou mal. Só posso ter um acesso existencial adequado à saúde quanto a tomo como a minha própria saúde, e não como aquilo que observo nos outros. Mas, para fazer isso, tenho de assumir que o que está em jogo na questão da saúde é meu modo de ser-no-mundo, minha existência como ser-para-amorte. Minha saúde, mesmo quando ainda não sei o que é, posso ver que está entranhada naquilo que compreendo como minha existência. Compreender minha saúde é compreender a mim mesmo como estando num jogo existencial, que inclui o tempo e a história, o que posso ser no mundo e abarca a perspectiva angustiante da morte. É assim que cada um de nós pode ser convertido ao modo próprio de indagar existencialmente sobre a saúde, sendo este, simultaneamente, um modo de indagar sobre a compreensão dos modos de ser do Dasein, tanto na cotidianidade quanto em suas possibilidades mais próprias.

O Dasein é um ser-para-a-morte, já que a morte lhe é a possibilidade de se compreender como estando em jogo, enquanto um ser lançado ao mundo: a morte é o seu "poder-ser mais próprio, irremissível e insuperável" 4 . O homem se diferencia dos animais porque, primeiro, tem o dom da linguagem, e, segundo, porque, sendo o ser do Dasein, compreende a si mesmo como um ser-para-a-morte. $O$ ser do Dasein desde sempre se compreende envolvido em dois modos existenciais que se articulam numa unidade e que são modos de ser do cuidado: a) a ocupação, que se dá no encontro com entes dispostos para uso, ou seja, entes que estão à mão (mundo da manualidade); b) a preocupação, que se dá em relação à presença de outros entes que têm a característica peculiar do Dasein. Neste sentido, o Dasein jamais está isolado, mas surge e se compreende situado numa totalidade criada por esses dois modos de ser no mundo. Por isto, a análise existencial nunca é uma análise da "subjetividade", mas da existência mesma, que se dá sempre num mundo circundante, envolvendo tanto o que entendemos como sociedade como o que entendemos como meio ambiente. O Dasein, antes de tudo, é um ser que cuida ao se descobrir 
"lançado ao mundo". O cuidado é o ser-no-mundo do Dasein: o Dasein, em sendo, mostra cuidado. O que se denomina "cuidado em saúde" remete a esses dois modos fundamentais do Dasein e de sua forma de ser como cuidado. Todo cuidado de saúde, numa compreensão do concreto, deriva da combinação possível desses dois modos de ser: manualidade (aspecto técnico, que usa instrumentos tais como os medicamentos) e preocupação (porque se dirige a um ente que tem o modo de ser do Dasein, o homem).

O Dasein está originalmente numa disposição, que pode ser descrita resumidamente como humor. O humor é essencialmente variável $e$ indica como estou: bem ou mal, alegre ou deprimido, estranho ou tranqüilo. A disposição é o modo de ser do Dasein que pode fazer com que se defronte consigo mesmo e com sua responsabilidade de ser e de se tornar, ao estar entregue a si mesmo. No entanto, a rápida passagem de um humor a outro faz com que o Dasein se mantenha mais que nada dedicado à ocupação e à preocupação no mundo, ou seja, às tarefas e relacionamentos que lhe são habituais na cotidianidade.

Por outro lado, o Dasein, de algum modo, originalmente se compreende como um poder-ser ou possibilidade de ser. Esta compreensão sustenta a abertura do Dasein para todas suas possibilidades, tanto as que foram no passado (as que deixou passar), como as possibilidades presentes $e$ as futuras. Nesta compreensão, o Dasein sabe como anda, isto é, "a quantas anda o seu poder ser".

Quando me pergunto sobre minha própria saúde, o humor e a compreensão estão sintonizados entre si no que sou, no meu Dasein. Isto significa que a compreensão da saúde, como qualquer outra a respeito do simesmo, não se dá num movimento intelectual puro, separado do humor ("sentimentos"). Toda compreensão da minha própria saúde é sustentada pelo humor.

Dado o pressuposto de um modo próprio de indagar sobre a saúde e a existência, podemos nos deslocar tentativamente para o conteúdo da compreensão existencial da saúde. O que segue é apenas um passo inicial para a analítica existencial da saúde.

O padecimento (do latim patescere, associado ao grego pathos (?), sofrimento, paixão). O padecimento é um conjunto dos fenômenos existenciários, radicados no cuidado, no humor e na compreensão do ser pelo Dasein: é, em primeiro lugar, esse emaranhado de sofrimentos que tenho enfrentado e ainda, por certo, enfrentarei; esta e outras doenças, esta e outras dores, esta e outras culpas, esta e outras crises de ansiedade, esta e outras formas de me sentir incapaz.

O padecimento é também meu modo de ser no mundo, modificado, isto é, defectivo em relação ao ser são; é o modo diferente como me entrego a minhas ocupações e relações com os outros, sob efeito desse emaranhado de sofrimentos. Isto porque não ocorre que, em primeiro lugar, eu padeça, para, posteriormente, conforme vá melhorando ou me restabelecendo, possa voltar ao mundo. O Dasein não se retira do mundo na vigência do padecimento; com efeito, isto só acontece com a morte. O padecimento dá-se ao mesmo tempo em que o Dasein é, enquanto cuidado, nos modos da ocupação e preocupação. A ocupação (execução de tarefas, entretenimento etc.) e a preocupação (junto a outros) dão-se como modos de ser modificados na vigência do padecimento: 
ocupo-me no mundo de outra maneira. Por exemplo, posso chegar tarde ao trabalho, tomar um táxi em vez de dirigir meu próprio carro, posso dirigir um carro especialmente adaptado para mim (se tenho alguma forma de invalidez). A preocupação também se modifica: posso prestar menos atenção às pessoas ou pedir aos outros que me ajudem em alguma tarefa ou diretamente que cuidem de mim.

Se, no padecimento, o Dasein se sente autorizado a modificar seu modo de ser no mundo, também o mundo está autorizado a se modificar para acolher o padecimento: por exemplo, as ambulâncias têm prioridade no trânsito; os banheiros $e$ as calçadas são adaptados para que os incapacitados possam ter acesso em cadeiras de rodas etc.

O Dasein padece numa totalidade, não só pelo que sente, mas pelo que faz continuamente como ser-no-mundo: não sei distinguir onde termina a culpa que me rói por dentro e onde começa essa coisa que os médicos chamam de alergia (talvez sejam ambas que me fazem espirrar sem cessar...). Assim, existencialmente, não há um padecimento que seja determinável como um ente particular, uma coisa só, tal como a medicina busca fazer ao distinguir as doenças enquanto unidades do diagnóstico.

A distinção entre formas de padecimentos físicos, psíquicos e espirituais só é possível com referência ao conhecimento de uma autoridade médica ou religiosa, embora o senso comum também acabe se orientando por essas distinções. A medicina oficial trata de diferenciar um ente do padecimento $e$ classificá-lo em tipos nosológicos, separados daquilo que é essa totalidade. Contrariamente, certas correntes alternativas da medicina (como a homeopatia) declaram que buscam determinar exatamente aquilo que identifica o Dasein em seu padecimento e dizem poder apreender a unidade de seu padecimento em meio à multiplicidade das queixas do paciente, de suas enfermidades e particularidades (modo de ser-no-mundo). É preciso levar em conta, portanto, que, nesse plano geral da análise existencial da saúde, não cabe a interpretação das causas ou dos modos de se apresentar das enfermidades.

Por outro lado, o padecimento que nomeamos é sempre algo peculiar ao homem e nada do que se diz aqui pode ser estendido a uma interpretação da saúde animal.

O padecimento, em suas possibilidades existenciárias, está essencialmente fundado na angústia, da qual ninguém pode ser efetivamente "curado". Pela angústia, o Dasein pode defrontar-se com suas possibilidades mais próprias, saindo da impessoalidade do mundo cotidiano. O significado existencial do padecimento encontra-se nas transformações do cuidado: o padecimento levame a me preocupar comigo mesmo e confrontar-me com o que sou e quero ser; posso receber generosamente a atenção e o carinho dos outros; posso me retirar das ocupações no mundo e ter espaço e tempo para estar comigo mesmo. Com isso, há a chance de que eu saia do modo impessoal de ser-nomundo, e me entregue à angústia, porque, neste dar-se tempo, o Dasein incomoda-se com suas possibilidades de poder-ser e com seu ser-para-a-morte. Entregando-me à angústia, posso me assumir nas possibilidades que me são mais próprias e tomar a decisão de forjar meu projeto singular de ser-nomundo. Por outro lado, posso contornar a angústia ou não experimentá-la por completo. Perturbado, busco "deixar pra lá” a angústia, para me 
restabelecer, voltar a ser o que eu era antes, na mundanidade cotidiana, onde me espera um bem-estar confortável.

Ainda quando o padecimento estreita meu projeto existencial em meu horizonte de possibilidades, ele me ajuda a fazer de mim uma pessoa sem igual: afinal, sou o único a padecer no mundo desta maneira. Estou lançado ao mundo como ser que padece desta maneira e, graças a isto, sou reconhecido $e$ acolhido. Assim, o padecimento é sempre um modo de ser singularizador e, por isto, tem de ser compreendido nessa condição de particularidade, em sua dinâmica ôntica, existenciária.

O padecimento abre essas duas possibilidades ao Dasein: de uma parte, pode deixá-lo entregue a sua angústia e preparar o advento do modo de ser mais próprio; de outra parte, pode trazer o anseio da recuperação no modo não-modificado de ser no mundo, que é a reinserção na mundanidade cotidiana, com sua familiaridade tranqüilizadora.

o socorro. Como não padeço no vazio, mas no mundo, com minhas ocupações e preocupações, mais ou menos modificadas, e que "estão a esperar por mim", tenho de lidar com meu padecimento para continuar a ser quem sou. O socorro é aquilo que me permite lidar com meu padecimento $e$ ir adiante no cotidiano. Tem o modo de ser do cuidado na preocupação, mas é dotado de manualidade: tenciona buscar um efeito bem definido, que é o sair do padecimento. Na sua origem, constitui uma modificação da preocupação, ou seja, do meu modo de ser com os outros e comigo mesmo, em que me sinto compelido a buscar ajuda e ajudar-me de algum maneira. Assim, surge pela aflição e pela compreensão de que "estou mal" e que preciso de ajuda urgente.

O cuidado joga o Dasein no modo de ser existenciário do socorro: busco não só isto e aquilo, mas tudo que encontro à mão. Assim, o socorro acaba por fazer o Dasein recorrer a uma ampla gama de possibilidades, no plano da manualidade do cuidado. Mas o socorro não dá lugar apenas a uma ajuda emergencial ou paliativa. Qualquer tipo de ajuda é ansiado e bem recebido. Por isso, o socorro tem um destino existencial indeterminado e assinala apenas que o Dasein está lidando com seu padecimento para seguir adiante no mundo.

O restabelecimento. O restabelecimento é a modalidade existenciária que faz o Dasein, sempre que pode e o mais rapidamente possível, retomar seu modo de ser na cotidianidade, aquilo que lhe é familiar. É, ao mesmo tempo, o objetivo e percurso do que se chama usualmente de cura.

Desde sempre, o Dasein se encontra lançado ao mundo, que é o espaçotempo da ocupação e da preocupação. O mundo do Dasein configura-se como a cotidianidade, ou seja, o conjunto repetitivo de tarefas e de preocupações de todos os dias, em que o Dasein se perde numa efervescência de coisas a fazer, de opiniões e de falas intermináveis (o falatório). Este é o modo impessoal de ser-no-mundo, mas é também, por assim dizer, o modo de ser regular, ordinário, "normal", do Dasein. Fechando suas possibilidades, o Dasein deixa de se ocupar consigo e com seu ser-para-a-morte que lhe mais próprio. $\mathrm{O}$ cotidiano revela-se, para ele, um ambiente seguro e confortável, um lugar para estar em paz e em bem-estar. Por isto, o Dasein foge do padecimento e busca, de novo, pôr-se por inteiro nesse modo de ser da cotidianidade, onde encontra tranqüilidade e bem-estar. 
O restabelecimento é tudo o que sinto e faço na rota que me permite voltar à plenitude da cotidianidade. Sinto-me, finalmente, bem e posso voltar às ocupações $e$ às preocupações que anteriormente me eram habituais, deixando de lado as modificações que adotei durante o padecimento. Pouco a pouco me restabeleço num mundo que me é familiar. Por isto, posso deixar para trás o socorro.

Mas é possível que, nesse retorno à minha situação habitual, o padecimento tenha simplesmente se esquivado e permaneça oculto algures. Escondeu-se em um desvão ou foi esquecido, suprimido, excluído. Mas certamente subsiste em potência. Pode reaparecer, revestido de outra figura ou com a mesma figura que antes havia se revelado. Assim, o padecimento não findou, mas apenas deixou temporariamente de obstruir ou modificar o meu modo de ser-no-mundo.

o reatamento. Ao longo do curso temporal em que lida com seu padecimento, o Dasein, compelido pelo cuidado e pela angústia, pode decidir projetar-se em suas possibilidades de ser mais próprias. Isto só pode ocorrer se não foge da angústia nem se refugia no padecimento como forma de ser singular.

A angústia não é algo que surge a partir de algum ente específico que venha ao encontro do Dasein (como ameaça ou outra característica qualquer). Fundamentalmente, a angústia se angustia com o próprio ser-no-mundo. Mas a angústia é a condição necessária para que o Dasein projete-se no mundo com uma nova visão de suas ocupações e de suas preocupações. É uma forma de ser que singulariza o Dasein; em outras palavras, confere identidade a seu projeto de vir-a-ser. A angústia envolve um sentir-se estranho, desconfortável, que já se faz presente no padecimento, e do qual o Dasein, no modo existenciário do socorro, é tentado a escapar. A angústia opõe-se ao bem-estar da cotidianidade; no entanto, é justamente ela que desenha o horizonte das possibilidades mais originais do Dasein.

A angústia é, também, um angustiar-se com o ser-para-a-morte, a morte como uma possibilidade própria, pessoal, do Dasein. Por isto, o Dasein foge da angústia, que acompanha o padecimento, em busca de um rápido restabelecimento no mundo cotidiano. Aí, sente-se em condições de tratar da morte em forma impessoal: é algo que acontece aos outros e não a si, é apenas um risco, em vez de ser o que lhe é de fato, a possibilidade mais própria ou mais decisiva. Mas a antecipação da morte é a possibilidade irremissível do Dasein, é a possibilidade que o libera para existir de modo mais próprio e para um modo próprio de compreender sua saúde.

Mas posso dar-me a escolha de me confrontar por inteiro com a angústia, $e$ reconhecer que há uma tarefa que me pertence, que tenho, desde logo, a cumprir, lidando com meu padecimento. O reatamento surge nesse reencontro do Dasein com seu ser-no-mundo, em que, por assim dizer, refaz sua totalidade existencial. Como desde sempre sou "junto ao mundo" e jamais posso ser "desatado" ou "isolado", esse re-atar é apenas o que chamamos de uma impressão: é o que posso entender existenciariamente em minha exaltação e alegria, como um nascer de novo, vir novamente ao mundo em que sempre sou e do qual nunca saí. O que isto pode significar ontologicamente é que me ponho no horizonte de todas as minhas possibilidades no modo próprio do Dasein: sou por inteiro livre em minhas 
possibilidades, e não naquilo que a efervescência das ações do mundo impessoal me dá a entender como obrigação. Deixo para trás o ser-nomundo impessoal e cotidiano, e singularizo-me em meu projetar-me para as novas possibilidades abertas no meu ser-no-mundo.

No reatamento, o socorro a que me entreguei deixa de ser tomado como um curativo, uma ajuda providencial. O socorro pode ser um suporte para meu reatamento, mas é o reatamento, em seu lugar, que se releva como a tarefa que me é mais própria. Evito fazer do socorro uma ponte rápida e eficaz para chegar, logo, a meu restabelecimento. Reatamento não é um padecimento remediado para que o Dasein siga adiante; é, ao contrário, a condição em que o Dasein refaz aquilo que ele é, nos modos de ser da ocupação e da preocupação. Mas já de si, o padecimento é uma totalidade que não pode ser dividida em múltiplos aspectos, tais como: os corporais, os psíquicos e os espirituais. O reatamento envolve, desde logo, a totalidade do Dasein $e$ a totalidade daquilo que esses aspectos analíticos representam, porque, de outro modo, seria apenas um restabelecimento.

O que acontece, então, com o padecimento quando se dá o reatamento? Pode desaparecer ou não. Pode desaparecer porque, na origem, surgiu de meu modo anterior de ser-no-mundo na cotidianidade. Ou pode persistir, mas não mais me perturba como fazia antes, porque aprendi a conviver com o padecimento e com a angústia que lhe é natural: não simplesmente para seguir adiante na mundanidade cotidiana, mas em sendo de uma maneira própria, à altura da liberdade do Dasein. O reatamento é essa recuperação de uma totalidade existencial que é minha, mas foi perdida no modo impessoal de ser. Mas o reatamento não diz respeito só ao modo de compreender a saúde e de apresentar como são para si e para os outros. É ao mesmo tempo uma recuperação da essência da saúde e o alcance da existência própria.

Porém, o reatamento não deve ser tomado no sentido de um episódio único e definitivo. Ele inaugura as possibilidades de um novo ciclo existencial. Daí em diante, o Dasein está confrontado com as escolhas que possa fazer nesse modo próprio e pessoal de ser, assumindo por inteiro sua responsabilidade pelas ocupações e preocupações que dele fazem um ser-nomundo. 


\section{Referências}

AYRES, J. R. C. M. Cuidado e reconstrução das práticas de saúde. Interface - Comunic., Saúde, Educ., v.8, n.14, p.73-92, set.2003-fev.2004.

AYRES, J. R. C. M. Norma e formação: horizontes filosóficos para as práticas de avaliação no contexto da promoção da saúde. Ciênc. Saúde Coletiva, v.9, n.3, p.583-92, 2004.

BRESSAN, V. R.; SCATENA, M. C. M. O cuidar do doente mental crônico na perspectiva do enfermeiro: um enfoque fenomenológico. Rev. Latino-am. Enferm., v.10, n.5, p.682-9, 2002.

CAPRARA, A. Uma abordagem hermenêutica da relação saúde-doença. Cad. Saúde Pública, v.19, n.4, p.923-31, 2003.

CAPRARA, A.; VERAS, M. S. C. Hermenêutica e narrativa: a experiência de mães de crianças afetadas por epidermólise bolhosa congênita. Interface - Comunic., Saúde, Educ., v.9, n.16, p.13146, 2005.

HEIDEGGER, M. Ser e Tempo. Petrópolis: Vozes, 2001a. 2 v.

HEIDEGGER, M. Seminários de Zollikon. Petrópolis: Vozes, 2001b.

LOPARIC, Z. Binswanger, leitor de Heiddeger: um equívoco produtivo? Nat. Hum., v. 4, n. 2, 2002.

LOPARIC, Z. Heidegger and Winnicott. Nat. Hum., v.1, n.1, 1999.

LOPES, R. L. M.; SOUZA, I. E. O. A fenomenologia como abordagem metodológica: compartilhando a experiência de mulheres que buscam a prevenção do câncer cérvico-uterino. Rev. Latino-am.

Enferm., v.5, n.3, p.5-11, 1997.

NOGUEIRA, R. P. Para un análisis existencial de la salud. Interface - Comunic., Saúde, Educ., v.10, n.20, p.333-45, jul/dez 2006.

La ontología fundamental de Heidegger en Ser y Tiempo ha servido como fuente de inspiración para investigadores en las áreas de la salud mental y de la salud colectiva, a pesar de las dificultades de la interpretación de esa obra. La comprensión errónea de Binswanger, en la tentativa de transportarla al psicoanálisis, sirve de ejemplo y es expuesta brevemente con base en el análisis detallado realizado por Loparic. En este artículo, el autor asume que el lenguaje antimetafísico de Heidegger puede ayudar a cerrar lo que él llama grieta ontológica entre la salud mental y la salud del cuerpo. En la primera parte, el artículo recapitula algunos equívocos que pueden ser cometidos al interpretar sobre la ontología de Heidegger y delinea los criterios de no-objetivación y no-determinismo. En la segunda, el autor aporta su contribución personal, al explicitar su propia interpretación de la analítica existencial de la salud, articulada alrededor de términos tales como padecimiento, ayuda y religación.

PALABRAS CLAVE: Ontología. proceso de la salud-enfermedad. existencialismo. 


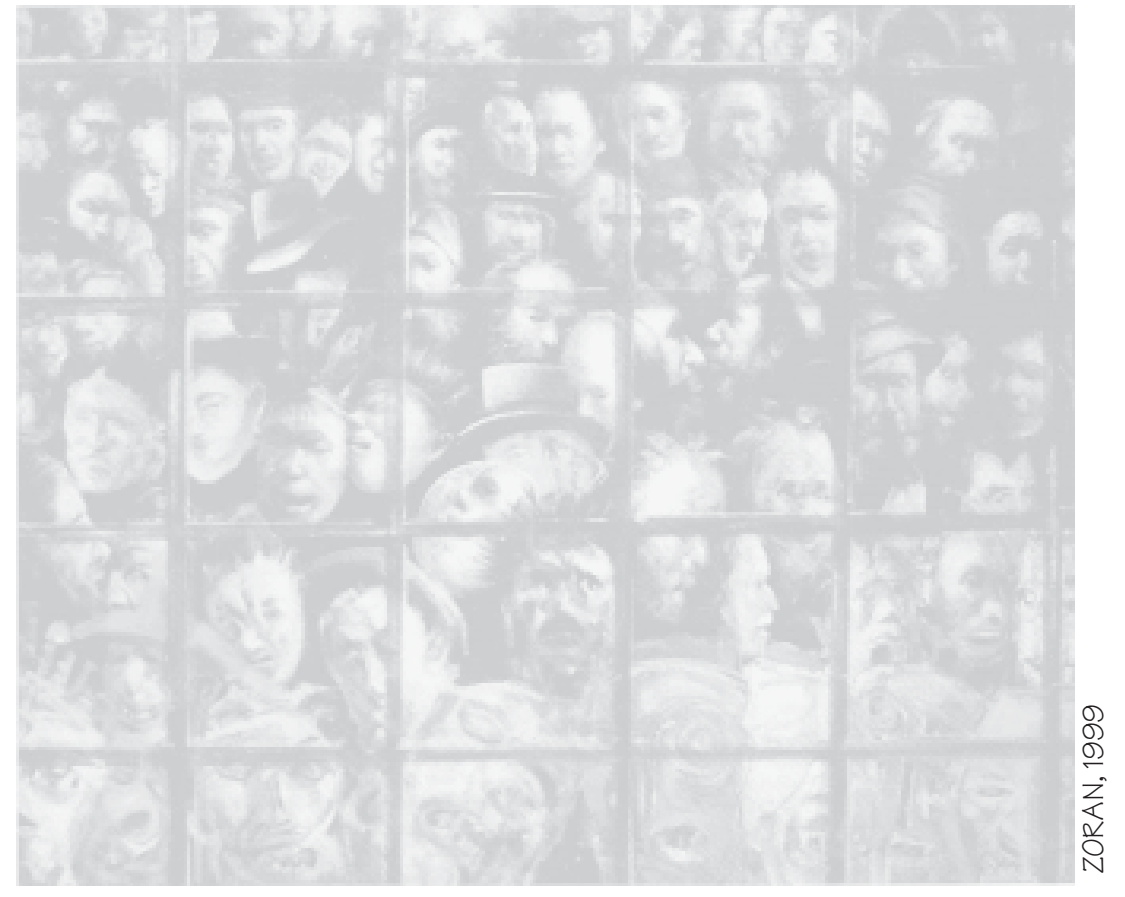

